\title{
Vocabulary Development and Trajectories of Behavioral and Emotional Difficulties Via Academic Ability and Peer Problems
}

\author{
Elizabeth M. Westrupp (iD \\ La Trobe University and Deakin University \\ Cristina McKean and James Law \\ Newcastle University
}

\author{
Sheena Reilly \\ Menzies Health Institute Queensland \\ Fiona Mensah \\ Murdoch Children's Research Institute
}

\author{
Jan M. Nicholson \\ La Trobe University
}

\begin{abstract}
This study investigates associations between trajectories of children's vocabulary development and subsequent behavioral and emotional difficulties via two potential mediating mechanisms; literacy and peer problems. Nationally representative data from 4,983 Australian children were used to examine trajectories of receptive vocabulary (4-5, 6-7, and 8-9 years) and hyperactivity-inattention, conduct problems and emotional symptoms $(8-9,10-11,12-13,14-15$ years), and literacy and peer problems (8-9 years). Lower growth in vocabulary was related to trajectories of hyperactivity-inattention, conduct problems, and emotional symptoms. Literacy was a key mediator explaining these associations. Results were consistent for children below the 50th percentile for vocabulary at $4-5$ years compared to the full sample. These findings suggest that early literacybased interventions may alleviate declining academic, emotional and behavioral functioning in adolescence.
\end{abstract}

Children with early language problems have higher rates of behavioral and emotional difficulties later in childhood compared to other children (Beitchman et al., 2001; Tomblin, Zhang, Buckwalter, \& Catts, 2000). The majority of the evidence has focused on clinical samples using clinical cut-points, but evidence from the general population and in

This article uses confidential unit record files from the Longitudinal Study of Australian Children (LSAC) survey. The LSAC project was initiated and funded by the Commonwealth Department of Social Services (formerly the Department of Families, Housing, Community Services and Indigenous Affairs) and was managed by the Australian Institute of Family Studies. The findings and views reported in this article are those of the authors and should not be attributed to these services. We thank all the families participating in the LSAC study.

Conflict of Interest: Elizabeth Westrupp and this study were supported by the Centre of Research Excellence in Child Language (Australian National Health and Medical Research Council NHMRC grant 1023493). Elizabeth Westrupp and Jan M. Nicholson were supported by the Australian Communities Foundation through the Roberta Holmes Transition to Contemporary Parenthood Program (Coronella sub-fund) at La Trobe University. Fiona Mensah was supported by an NHMRC Early Career Fellowship 1037449 and Career Development Fellowship 1111160. Authors have no other relevant disclosures.

Correspondence concerning this article should be addressed to Elizabeth Westrupp, Faculty of Health, School of Psychology, Deakin University, Melbourne Burwood Campus, 221 Burwood Highway, Burwood, Victoria 3125, Australia. Electronic mail may be sent to elizabeth.westrupp@deakin.edu.au. studies considering the full range of functioning have also found consistent associations (Bretherton et al., 2014; Clegg, Law, Rush, Peters, \& Roulstone, 2015; Tomblin et al., 2000). Nevertheless, despite one in five children having problems in one or more of these development domains (Reilly et al., 2010), the association between language and subsequent behavioral and emotional difficulties is poorly understood. The current study focuses on receptive vocabulary development across early childhood. There is currently little evidence about how the developmental trajectory of children's receptive vocabulary affects later trajectories of behavioral and emotional difficulties; and there is limited theoretical understanding of the mechanisms by which they are likely to be related.

Although research on trajectories of vocabulary has been limited, the relationship between early vocabulary difficulties and developmental language disorders has been well recognized. Early vocabulary skills are linked to communication development, including verb growth (Longobardi, Spataro, Putnick, \& Bornstein, 2017), grammar (Bates \&

(C) 2019 Society for Research in Child Development All rights reserved. 0009-3920/2019/xxxx-xxxx DOI: $10.1111 /$ cdev.13219 
Goodman, 2001), and related skills, such as school readiness (Morgan et al. 2015). Early language difficulties are related to a multitude of poor outcomes, including lower health-related quality of life (Feeney, Desha, Ziviani, \& Nicholson, 2012), difficulties in social communication and personal relationships (Schoon, Parsons, Rush, \& Law, 2010), poorer educational outcomes, and reduced career opportunities (Schoon et al., 2010). Studies have shown that children with language difficulties are also at increased risk for behavioral (Botting \& Conti-Ramsden, 2000; Bretherton et al., 2014) and emotional difficulties (Goh Kok Yew \& O'Kearney, 2015). Behavioral and emotional difficulties are experienced by approximately $14 \%$ of children (Lawrence et al., 2015). High levels of externalizing behavior problems in early childhood are associated with future conduct disorder and antisocial behavior problems (Bennett et al., 1999). Emotional problems refer to anxiety and depressive symptoms, which are often examined together given their high degree of co-occurrence (Eisenberg et al., 2001).

\section{Change in Language and Behavioral and Emotional Difficulties Over Childhood}

Most of the existing clinical or population research has examined associations between child language, and behavioral and emotional problems cross-sectionally, or has used a longitudinal design limited to defining early impairment in one domain and outcomes in the other domain at later stages of child development (Beitchman et al., 2001; Law, Rush, Clegg, Peters, \& Roulstone, 2015; St Clair, Pickles, Durkin, \& Conti-Ramsden, 2011; e.g., Tomblin et al., 2000). In addition, these analyses have focused on clinical measures of language rather than on receptive vocabulary, and assumed relative within-person stability in language and behavioral and emotional difficulties across childhood. However, there is now strong evidence from longitudinal research showing a high level of variability in children's trajectories of language development and thus in rates of language impairment over time, with the highest level of variability evident in early childhood (Beitchman et al., 2008; Snowling, Duff, Nash, \& Hulme, 2016; Song et al., 2015; Ukoumunne et al., 2012); and in rates of behavioral and emotional problems across childhood and adolescence (Spira \& Fischel, 2005; Visser, Ende, Koot, \& Verhulst, 1999). Consequently, research has demonstrated variation in the association between language, and behavioral and emotional difficulties over childhood, with associations becoming stronger over time (Bretherton et al., 2014).

An important next step for research is to examine the association between child language and subsequent behavioral or emotional difficulties while accounting for change in both domains over time. One study investigated the association while accounting for change in child outcomes (but not language). Menting, van Lier, and Koot (2011) found that early language skills (Grade 2) were associated with an increase in peer rejection and externalizing behavior problems modeled over five time-points from kindergarten to Grade 4. However, the timing of the single language assessment fell in the middle of the assessments of the peer rejection and behavior assessments, preventing a clear understanding of the sequence of these associations. The early childhood period is characterized by rapid development in language; in contrast, specific behavioral or emotional difficulties most commonly develop in the middle childhood and adolescence period (Spira \& Fischel, 2005). If the rate of language growth is an important predictor of children's behavioral or emotional trajectories, this suggests innovative school-based early intervention options may be important for preventing language and behavioral or emotional difficulties.

The way in which language affects children's trajectories of behavior and emotion development is likely to vary by the type of problem. Hyperactivity-inattention, conduct problems, and emotional symptoms have all commonly been found to be associated with child language problems (Botting \& Conti-Ramsden, 2000; Bretherton et al., 2014; Goh Kok Yew \& O'Kearney, 2015). While hyperactivityinattention symptoms and conduct problems tend to emerge in early-to-middle childhood, emotional symptoms related to mood and anxiety disorders often emerge later and are more prevalent in adolescence (Kessler et al., 2005). Although many studies have examined these outcomes separately (generally at one cross-sectional time-point), none have done so while examining the effect of change in language and behavioral or emotional difficulties over time.

\section{Potential Mechanisms}

Examination of potential mechanisms will assist in developing more precise intervention models. One possibility is that children who have early or developing language problems are more likely to have disrupted peer relationships. This is consistent with Redmond and Rice's Social Adaptation Model, 
which contends that children with language impairment lack the verbal resources required to manage the communication demands of their environment (Redmond \& Rice, 1998). In turn, this leads to children having reduced or problematic interactions with peers, and thus developing social difficulties and an increased risk for behavioral and emotional problems. A number of studies have shown that language problems are associated with higher rates of social difficulties (Im-Bolter, Cohen, \& Farnia, 2013; Mok, Pickles, Durkin, \& Conti-Ramsden, 2014); and one study has provided evidence for mediation, where the development of peer rejection from kindergarten to Grade 4 mediated the association between language at Grade 2 and the developmental trajectory of externalizing problems from kindergarten to Grade 4 (Menting et al., 2011). The next step is to investigate these associations while investigating the effect of change in language ability over time, using measures that do not overlap in time (as those in the Menting study did) to allow a better investigation of directionality.

A second possible mechanism explaining the association between language, and behavioral or emotional difficulties may be related to children's academic ability. Beitchman and colleagues proposed that poor academic achievement may arise due to poor early language development, where low achievement then leads to the development of social, behavioral, and emotional problems as children become disengaged from school (Beitchman, Brownlie, \& Wilson, 1996). Previous research has shown that children with language problems exhibit higher rates of reading disorder (Song et al., 2015), and lower literacy or poorer educational outcomes (Snowling et al., 2016). Early evidence for the role of literacy was provided from cross-sectional data from a large study of second-grade children (aged 7-8 years) in the United States, testing a mediation model, with findings showing that the association between children's language impairment and subsequent behavioral disorder was explained by reading disability (Tomblin et al., 2000). However, the possible causal mechanisms in this model require further investigation using longitudinal data.

\section{The Current Study}

We seek to investigate the nature of the association between children's development of receptive vocabulary and subsequent behavioral (hyperactivity-inattention and conduct problems) or emotional difficulties. Instead of assuming stability in one or both domains, we challenge dominant conceptualizations of the association by employing a structural equation modeling (SEM) framework and growth curve modeling to test how the trajectory of children's vocabulary development over early-to-middle childhood is related to their trajectories of hyperactivity-inattention, conduct problems, and emotional symptoms from middle childhood to early adolescence. In addition, we will contribute to a theoretical understanding of these prevalent childhood disorders and guide future intervention by investigating the role of children's peer relationships and academic ability in the association between child vocabulary and hyperactivity-inattention, conduct problems, and emotional symptoms. We will investigate three research questions (RQ):

RQ1: Is lower growth in receptive vocabulary over childhood (4-5, 6-7, and 8-9 years) associated with the emergence and trajectory of hyperactivityinattention, conduct problems, or emotional symptoms $(8-9,10-11,12-13,14-15$ years), over and above the known association with early vocabulary at 4-5 years? Given prior evidence showing variability in child language, and behavioral and emotional problems, over time (Beitchman et al., 2008; Snowling et al., 2016; Song et al., 2015; Spira \& Fischel, 2005; Ukoumunne et al., 2012; Visser et al., 1999), we expected that the rate of change in vocabulary would be associated with behavioral and emotional problems at 8-9 years, and with the rate of change in behavioral and emotional problems over childhood.

RQ2: Do peer problems or child academic ability (literacy, age 8-9) mediate the association between growth in receptive vocabulary $(4-5,6-7$, and 8 9 years) and subsequent trajectories of hyperactivity-inattention, conduct problems, or emotional symptoms (8-9, 10-11, 12-13, 14-15 years)? We expected that both peer problems and child academic ability would mediate the association between trajectories of vocabulary and behavioral and emotional problems.

RQ3: Do associations between trajectories of receptive vocabulary and hyperactivity-inattention, conduct problems, or emotional symptoms differ depending on early receptive vocabulary? We will test associations separately for the whole group of children, and then for children below the 50th percentile for vocabulary at age 4-5 years. Given research showing associations between vocabulary and behavioral and emotional problems in both clinical and population groups (Bretherton et al., 2014; Clegg et al., 2015; Tomblin et al., 2000), we expected associations to be consistent for the whole 
sample compared to children in the lower 50th percentile for language at $4-5$ years.

We draw on biennial data from the Longitudinal Study of Australian Children (LSAC), spanning 10 years of childhood and adolescence. It is not possible to definitively test causality using observational data. However, we will investigate the sequence and timing of associations to inform an understanding of the longitudinal mechanisms underlying children's vocabulary and hyperactivity-inattention, conduct problems, and emotional symptoms. Although bidirectional effects between vocabulary and behavioral or emotional difficulties (i.e., hyperactivity-inattention, conduct problems, and emotional symptoms) are likely to occur across development (Law, Plunkett, \& Stringer, 2012), our study will focus on the association between early vocabulary and subsequent behavioral or emotional difficulties due to the restricted availability of the receptive vocabulary measure in the current study, assessed at the first three timepoints only $(4-5,6-7$, and $8-9$ years). Recent evidence supports this hypothesized direction of influence; findings from a longitudinal autoregressive cross-lagged analysis showed that receptive vocabulary was associated with later inattentivehyperactive and externalizing problems from 4 to 12 years more strongly compared to associations between inattentive-hyperactive and externalizing problems and later receptive vocabulary (Petersen et al., 2013). However, to account for potential bidirectional influences between vocabulary and hyperactivity-inattention, conduct problems, and emotional symptoms in early life, our models will control for prior child hyperactivity-inattention, conduct problems, and emotional symptoms at 45 years.

Analyses will also account for child nonverbal intelligence (Snowling et al., 2016), child age (Im-Bolter et al., 2013), and socioeconomic disadvantage (Law et al., 2015); factors known to influence the emergence and trajectory of vocabulary, behavior, emotional and peer problems, and academic functioning. Finally, we employ direct-assessment data for receptive vocabulary; teacher-report data for mediation variables; and mother-report data for child hyperactivity-inattention, conduct problems, and emotional symptoms, in order to prevent bias caused by single-source assessment methods. To rule out bias related to teacher and parent-report measurement, we also conduct sensitivity analyses using a national assessment measure for academic achievement in Grade 3, and child self-report data for hyperactivity-inattention, conduct problems, and emotional symptoms at available time-points (i.e., 10-11, 12-13, and 14-15 years).

\section{Method \\ Design}

The LSAC is a nationally representative prospective cohort study of Australian children and their families (Soloff, Lawrence, \& Johnstone, 2005). LSAC was approved by the Australian Institute of Family Studies Ethics Committee (Gray \& Sanson, 2005). Participating children were randomly selected in a two-stage cluster sampling design using Australian postcodes and the Medicare universal healthcare database (Soloff, Sanson, Wake, \& Harrison, 2007). We used data from the Kindergarten cohort across six time-points, comprising 4,983 children aged $4-5$ years at recruitment in 2004 (59\% initial response rate), and followed at 6-7 years (retention from Wave 1: 90\%), 8-9 years (retention from Wave 1: 86\%), 10-11 years (retention from Wave 1: 82\%), 12-13 years (retention from Wave 1: 80\%), and 14-15 years (retention from Wave 1: 74\%; Australian Institute of Family Studies, 2015). Data were collected by direct child assessment, questionnaires completed by the child's primary carer (97\% were biological mothers) and teachers, and via data linkage.

\section{Participants}

All children were included in the analyses $(N=4,983)$. At baseline (4-5 years), children were on average 57 months $(S D=2.6)$; half were male $(5.9 \%)$; and $13 \%$ were rated by their mothers as having fair or poor global health. At a family level, $15 \%$ of households were single parent families; $17 \%$ were households where English was not the main language spoken at home; $23 \%$ had fathers who had been born overseas.

\section{Measures}

To investigate the timing and sequence of effects, the mediating and outcome variables were examined progressively later in childhood compared to the child's vocabulary.

\section{Receptive Vocabulary (4-5, 6-7, and 8-9 Years)}

Vocabulary was assessed directly using an Australian-adapted short version of the Peabody Picture Vocabulary Test, 3rd ed. (Dunn \& Dunn, 1997; 
Rothman, 2003b). This measure was adapted using one-parameter (Rasch) item response modeling using 40 items divided into core, basal, and ceiling sets. Final estimates were transformed to a scale with a mean of 64 and a standard deviation of 8 prior to being released for open access. The final person separation reliability was .78 (Rothman, 2003a). Unstandardized (raw) scores were used in analyses.

Hyperactivity-Inattention, Conduct Problems, and Emotional Symptoms (8-9, 10-11, 12-13, and 1415 Years)

Mother-report on the hyperactivity-inattention, conduct problems, and emotional symptoms subscales of the Strengths and Difficulties Questionnaire (SDQ) were used to assess child behavioral or emotional difficulties at four time-points (Goodman, 1997). As a sensitivity analysis, child self-report versions of the hyperactivity-inattention, conduct problems, and emotional symptoms subscales were used at $10-11,12-13$, and 14-15 years (Goodman, Meltzer, \& Bailey, 1998). Parent, teacher, and self-report versions of the SDQ have been found to have satisfactory internal consistency $\left(M_{\alpha}=.73\right.$, cross-informant correlation $(M=.34)$ and retest stability after 4-6 months (.34; Goodman, 2001). Each subscale includes five items rated on a 3-point scale $(0=$ not true to 2 =certainly true) and were averaged together to form a total subscale score. Items for emotional symptoms included "Often unhappy, depressed or tearful; Nervous or clingy in new situations, easily loses confidence" (in the current study, $\alpha=.66-.72$ ); conduct problems, "Often fights with other children or bullies them; Steals from home, school or elsewhere" $(\alpha=.60-.63)$; and hyperactivity-inattention, "Good attention span, sees work through to the end [reverse coded]; Restless, overactive, cannot stay still for long" $(\alpha=.78-.80)$.

\section{Peer Problems (8-9 Years)}

Teacher-report on the peer problems subscale of the SDQ was used (Goodman, 2001). The five-items (e.g., "Rather solitary, prefers to play alone; Gets along better with adults than with other children") were rated on a 3-point scale $(0=$ not true to $2=$ certainly true) and were averaged together to form a total subscale score $(\alpha=.69)$. As above, the teacher version of the SDQ has been found to have satisfactory internal consistency.

\section{Academic Ability (8-9 Years)}

Teacher-report on the Academic Rating Scale was used to assess children's academic achievement in terms of language and literacy (eight-items; Rothman, 2009). For example, teachers were asked whether the child "Uses various strategies to gain information using print materials" or "Makes editorial corrections when reviewing a written draft." Items were rated on a 5 -point scale $(1=$ not yet to $5=$ proficient $)$ and averaged to create a continuous total score $(1-5 ; \alpha=.98)$. A sensitivity analysis used data from the Australian National Assessment Program-Literacy and Numeracy (NAPLAN) on child academic achievement in reading in Year 3 of primary (elementary) school (Daraganova, Edwards, \& Sipthorp, 2013). Data were available for $61 \%$ of the sample only due to issues with the timing of the data linkage.

\section{Model Covariates (4-5 and 6-7 Years)}

Mothers reported on their child's age. Socioeconomic position was a continuous, composite variable, ranking family position based on parent-report of parents' education, occupational prestige, and household income, with higher scores indicating higher socioeconomic position (Blakemore \& Strazdins, 2009). Children also completed the Matrix Reasoning test from the Wechsler Intelligence Scale for Children, 4th ed. (Wechsler, 2003) to assess nonverbal intelligence at 6-7 years.

\section{Statistical Analysis}

Data were prepared and cleaned using Stata version 15 (StataCorp LLC, 4905 Lakeway Drive, College Station, Texas 77845-4512, USA). Analyses for RQs 1 and 2 were conducted in Mplus version 7.3 (Muthén \& Muthén, 1998-2010). Models were weighted using cross-sectional weights from Time 1 (age 4-5) to account for nonresponse, and the Mplus stratification and cluster options were applied to account for the complex survey design (Sipthorp \& Daraganova, 2011). Maximum likelihood estimation with robust standard errors was used to handle missing data. Rates of missing data varied by time-point and variables; $14 \%$ of children had missing data on at least one of the vocabulary measures; $23 \%$ on the mother-report and $32 \%$ on the child-report SDQ subscales, up to $28 \%$ missing on the teacher literacy and peer problems subscale of the SDQ; and $40 \%$ missing on reading achievement. 


\section{Research Questions 1 and 2}

Latent growth curve analysis (i.e., growth modeling) was used to model longitudinal trajectories for child vocabulary at ages $4-5,6-7$, and 8-9, and mother-report of hyperactivity-inattention, conduct problems, and emotional symptoms at ages 8-9, 10-11, 12-13, and 14-15 (Model 1). Growth modeling estimates two latent variables for each set of repeated measures, the intercept (i.e., starting point) and the slope (i.e., rate of change). A structural model was specified to test direct and indirect associations between the variables. The intercept and slope for vocabulary were specified to predict the intercept and slope for hyperactivity-inattention, conduct problems, and emotional symptoms. The intercept and slope for each construct were correlated. To test indirect associations, the model was specified so that the intercept and slope for vocabulary predicted literacy and peer problems; and that literacy and peer problems predicted the intercept and slope for hyperactivity-inattention, conduct problems, and emotional symptoms.

Covariates (socioeconomic position and nonverbal intelligence) were entered to predict all of the dependent variables in the models. Mother-report of child hyperactivity-inattention, conduct problems, and emotional symptoms at 4-5 years were entered to predict each of the associated child outcomes at 8-9, 10-11, 12-13, and 14-15 years. Hyperactivity-inattention, conduct problems and emotional symptoms at $4-5$ years were also covaried with vocabulary at $4-5$ years. Due to a variation in child ages of approximately 18 months at each assessment, and in context of the sensitivity of vocabulary skills to differences in child age, the child vocabulary outcome variables were regressed on child age in months for the associated timepoint. All of the intercept and slope terms for child hyperactivity-inattention, conduct problems, and emotional symptoms at 8-9, 10-11, 12-13, and 1415 years were allowed to covary; as were measures assessed within the same time-point.

We report the chi-square goodness-of-fit statistic to determine model fit but given that it is less informative with large sample sizes (Byrne, 2012), a model was deemed to have good fit if the rootmean-square error of approximation (RMSEA) was $<.05$ (Byrne, 2012), standardized root-mean-square residual (SRMR) was $<.05$, and the comparative fit index (CFI) and/or the Tucker-Lewis index (TLI) had values $>.95$ (Hu \& Bentler, 1999).

Bias-corrected bootstrapped confidence intervals for estimates of direct and indirect associations are reported for all models (MacKinnon, Lockwood, \& Williams, 2004). We consider these results as well as $p$-values in relation to establishing evidence for tested associations in the models. The 'Model Indirect' function in Mplus with bootstrapping using replicate weights was used to compare the contribution of unstandardized and standardized indirect and direct effects of vocabulary on child outcomes. Given that the specified models examine paths between variables with negative correlations, we may find 'inconsistent' mediation effects, that is, where two or more effects in a mediation model have opposite signs, causing the total effect to be null or reduced (MacKinnon, Fairchild, \& Fritz, 2007). In this case, we will interpret the direct and indirect effects separately from the total effect, and present only data for indirect effects in-text.

\section{Sensitivity Analyses}

Model 1 was retested with two variations. Firstly, teacher-report of literacy (i.e., academic ability) was replaced with the national assessment measure of reading (sensitivity Model 1A). In the next model, the mother-report measures of child hyperactivity-inattention, conduct problems, and emotional symptoms at 8-9, 10-11, 12-13, and 14-15 years were replaced with child self-report measures at 10-11, 12-13, and 14-15 years (sensitivity Model 1B).

\section{Research Question 3}

The model specified for RQs 1 and 2 was repeated using a subpopulation of children defined as being below the 50th percentile for receptive vocabulary at $4-5$ years (Model 2).

\section{Results \\ Preliminary Statistics}

Correlations between model variables presented in Table 1 indicated that receptive vocabulary had a very small or no association with peer problems, moderate association with academic ability, and small associations with later hyperactivity-inattention, conduct problems, and emotional symptoms. Overall, correlations between mediators (peer problems and academic ability), hyperactivity-inattention, and conduct problems were small to moderate; and were small with emotional symptoms. Histograms presented in Figure S3 show the distributions, skewness, and kurtosis for all model variables. 


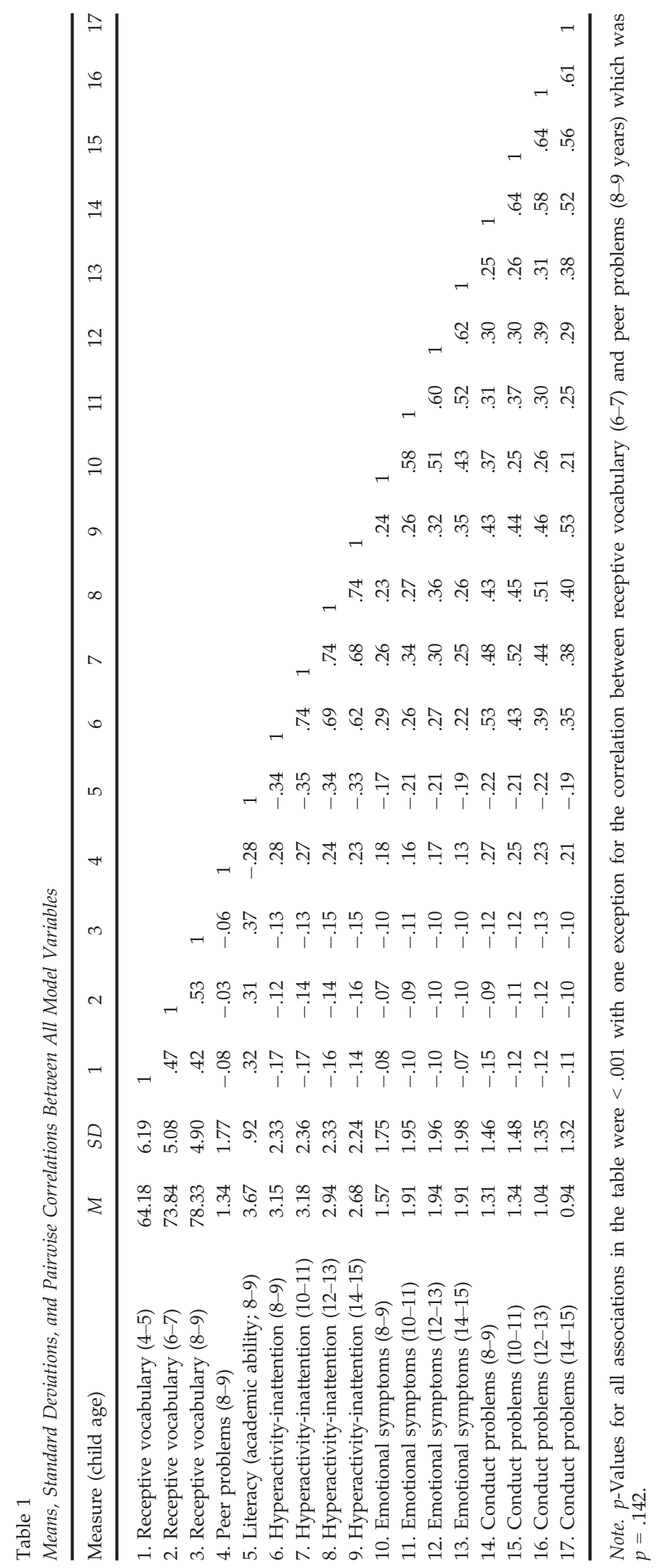




\section{Research Questions 1 and 2}

Figure 1 and Table 2 present results from Model 1 , and show regression coefficients from adjusted models examining the direct and indirect associations between vocabulary trajectories and trajectories of hyperactivity-inattention, conduct problems, and emotional symptoms. This model had good overall fit despite the inflated chi-square result related to the large sample and complex model, $\chi^{2}[d f]=722.677$ [170], $p<.000 ;$ RMSEA $=.026,95 \%$ CI [.024, .027]; CFI $=.980 ;$ TLI $=.968 ;$ SRMR $=.047$. All growth factors (intercepts and slopes) were significant, indicating linear change in each construct increasing over time.

RQ 1 sought to investigate whether growth in vocabulary exerts an additional independent influence on child outcomes over and above early vocabulary. We found that higher scores for child vocabulary at 4-5 years were associated with higher child hyperactivity-inattention at 8-9 years (intercept) and a lower slope (i.e., less rapid increase) in hyperactivity-inattention between 8-9 and 14-15 years. We also found that a higher slope (i.e., a more rapid increase) in vocabulary between 4-5 and 8-9 years was associated with higher child hyperactivity-inattention at 8-9 years and a lower slope in hyperactivity-inattention between 8-9 and 14-15 years. Direct associations between initial levels and growth in vocabulary and emotional symptoms or conduct problems were not evident. Higher vocabulary at 4-5 years and a more rapid increase in vocabulary were both associated with higher literacy, but not with peer problems at 89 years. Literacy was negatively associated, and peer problems were positively associated, with

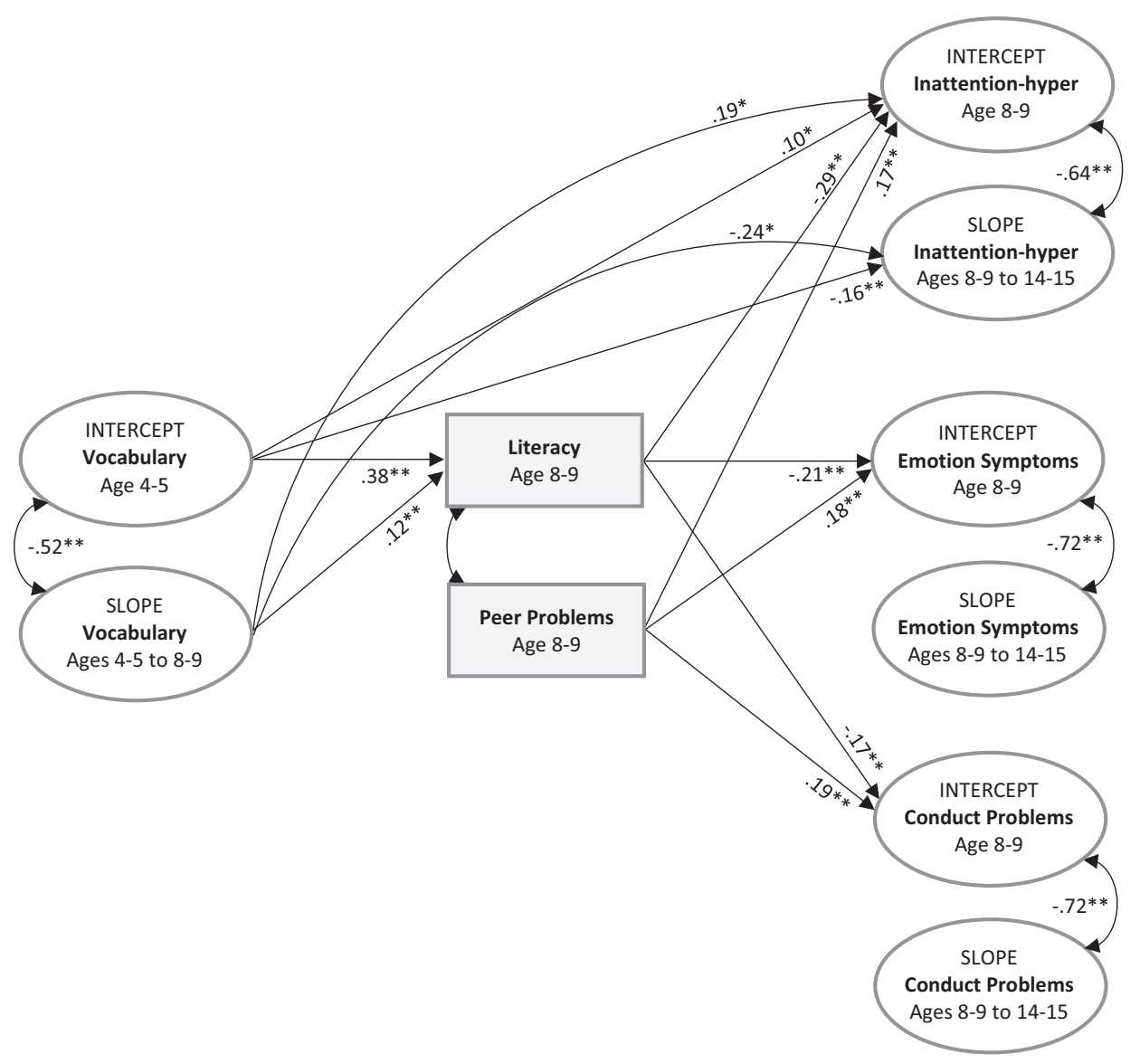

Figure 1. Findings for all children $(N=4,983)$, showing results $(p<.05)$, from a latent growth curve model, with direct relations between trajectories of receptive vocabulary and mother-report of hyperactivity-inattention, conduct problems, and emotional symptoms; and indirect relations via peer problems and literacy.

Note. Single-headed straight or curved lines represent standardized regression coefficients where $p<.05$. Models adjust for hyperactivity-inattention, conduct problems, and emotional symptoms at 4-5 years, socioeconomic position at 4-5 years, child age, and child nonverbal intelligence at 6-7 years. Emotion symptoms $=$ emotional symptoms.

$* p<.05 . * * p<.01$. 
Table 2

Direct and Indirect Relations Between Childhood Trajectories of Vocabulary and Hyperactivity-Inattention, Conduct Problems, and Emotional Symptoms, for All Children Together Versus Children With Normal or Low Language at 4-5 Years

Unstandardized regression coefficient $(95 \% \mathrm{CI})$
Standardized regression coefficient $(95 \% \mathrm{CI})$

Path

$.05(.01, .11)^{*}$

$.34(.07,1.09)^{\wedge}$

$-.02(-.03,-.01)^{*}$

$-.09(-.27,-.03)^{*}$

$.01(-.05, .05)$

$-.14(-.46, .10)$

$-.01(-.02, .01)$

$.00(-.07, .08)$

$-.01(-.04, .03)$

$.04(-.16, .25)$

$.00(-.01, .01)$

$-.02(-.08, .03)$

$.09(.07, .10)^{* *}$

$.10(.03, .19)^{* *}$

$-.01(-.03, .02)$

$.04(-.13, .30)$

$-.66(-.92,-.41)^{* *}$

$.20(.10, .30)^{* *}$

$.04(-.02, .10)$

$-.01(-.03, .01)$

$-.40(-.64,-.14)^{* *}$

$.18(.07, .30)^{* *}$

$.02(-.04, .07)$

$-.02(-.04, .01)$

$-.26(-.43,-.08)^{* *}$

$.15(.06, .22)^{* *}$

$.03(-.01, .07)$

$-.01(-.02, .01)$
$.10(.02, .22)^{*}$

$.19(.04, .38)^{*}$

$-.16(-.30,-.05)^{* *}$

$-.24(-.51,-.08)^{*}$

$.02(-.12, .11)$

$-.09(-.24, .06)$

$-.06(-.16, .05)$

$.01(-.17, .17)$

$-.01(-.12, .09)$

$.03(-.13, .18)$

$-.05(-.20, .08)$

$-.09(-.31, .11)$

$.38(.33, .44)^{* *}$

$.12(.02, .20)^{* *}$

$-.02(-.08, .05)$

$.03(-.08, .16)$

$-.29(-.40,-.19)^{* *}$

$.17(.09, .26)^{* *}$

$.09(-.04, .23)$

$-.04(-.14, .06)$

$-.21(-.33,-.07)^{* *}$

$.18(.07, .29)^{* *}$

$.04(-.08, .15)$

$-.07(-.17, .04)$

$-.17(-.28,-.06)^{* *}$

$.19(.09, .28)^{* *}$

$.11(-.05, .25)$

$-.04(-.16, .09)$

Model 2: children below the 50 th percentile for vocabulary at $4-5$ years $(N=2,120)$

Associations between independent and dependent variables

Hyper intercept ON RV intercept

Hyper intercept ON RV slope

Hyper slope ON RV intercept

Hyper slope ON RV slope

Emotion intercept ON RV intercept

Emotion intercept ON RV slope

Emotion slope ON RV intercept

Emotion slope ON RV slope

Conduct intercept ON RV intercept

Conduct intercept ON RV slope

Conduct slope ON RV intercept

Conduct slope ON RV slope
$.03(-.06, .13$

$.14(-.03, .35)$

$-.02(-.04, .01)$

$-.05(-.10,-.01)^{*}$

$-.01(-.09, .06)$

$-.03(-.22, .15)$

$-.01(-.03, .02)$

$-.02(-.07, .03)$

$-.01(-.08, .07)$

$-.03(-.16, .11)$

$-.002(-.02, .01)$

$.001(-.04, .04)$
$.05(-.08, .20)$

$.11(-.03, .23)$

$-.14(-.33, .05)$

$-.20(-.37,-.05)^{*}$

$-.02(-.15, .11)$

$-.02(-.17, .12)$

$-.04(-.19, .11)$

$-.06(-.22, .11)$

$-.02(-.17, .14)$

$-.04(-.19, .12)$

$-.02(-.24, .19)$

$.01(-.21, .25)$

Associations between independent and mediating variables

Literacy ON RV intercept

$.09(.07, .12)$

$.29(.20, .35)$

$.09(.03, .15)$

$-.02(-.09, .04)$

$.01(-.12, .15)$

$.14(.04, .22)$

$-.04(-.13, .06)$

$.01(-.10, .11)$ 
Table 2

Continued

\begin{tabular}{lcc}
\hline Path & $\begin{array}{c}\text { Unstandardized regression } \\
\text { coefficient }(95 \% \mathrm{CI})\end{array}$ & $\begin{array}{c}\text { Standardized regression } \\
\text { coefficient }(95 \% \mathrm{CI})\end{array}$ \\
\hline Associations between mediating and dependent variables & & $-.37(-.53,-.21)^{* *}$ \\
Hyper intercept ON literacy & $-.77(-\mathbf{1 . 1 2},-.43)^{* *}$ &. $\mathbf{1 7}(.06, .31)^{* *}$ \\
Hyper intercept ON peer & $.20(.06, .35)^{* *}$ & $.17(-.03, .38)$ \\
Hyper slope ON literacy & $.07(-.01, .16)$ & $-.06(-.24, .09)$ \\
Hyper slope ON peer & $-.01(-.05, .02)$ & $-.25(-.43,-.09)^{* *}$ \\
Emotion intercept ON literacy & $-.46(-.80,-.14)^{* *}$ & $.22(.06, .37)^{* *}$ \\
Emotion intercept ON peer & $.22(.06, .37)^{* *}$ & $.10(-.07, .27)$ \\
Emotion slope ON literacy & $.05(-.03, .13)$ & $-.10(-.25, .06)$ \\
Emotion slope ON peer & $-.03(-.06, .01)$ & $-.26(-.43,-.11)^{* *}$ \\
Conduct intercept ON literacy & $-.37(-.61,-.15)^{* *}$ & $.06(-.07, .20)$ \\
Conduct intercept ON peer & $.05(-.05, .16)$ & $.26(.02, .50)^{*}$ \\
Conduct slope ON literacy & $.06(.01, .12)^{* *}$ & $.11(-.09, .31)$ \\
Conduct slope ON peer & $.01(-.01, .04)$ & \\
\hline
\end{tabular}

Note. Models adjusted for hyperactivity-inattention, conduct problems, and emotional symptoms at 4-5 years, socioeconomic position at 4-5 years, child age, and child nonverbal intelligence at 6-7 years. Data in table are from bias-corrected bootstrapped confidence intervals (MacKinnon et al., 2004).

$\mathrm{RV}=$ receptive vocabulary; Hyper $=$ hyperactivity-inattention; $\quad$ Conduct $=$ conduct problems; Emotion $=$ emotional symptoms; Literacy $=$ academic ability; Peer $=$ peer problems; $\mathrm{ON}=$ dependent variable regressed on independent variable.

Bold-face indicates significant effects, as follows: ${ }^{\wedge} p \geq .05 . * p<.05 .{ }^{* *} p<.01$.

hyperactivity-inattention, conduct problems, and emotional symptoms at 8-9 years.

RQ 2 tested possible mediating mechanisms. Unstandardized and standardized results for total, total indirect, and direct effects with bias-corrected bootstrapped $95 \%$ confidence intervals are presented in Table S1. Correlations were also specified (replacing regression terms) between the independent and dependent variables in the final model in order to examine bivariate associations, and are presented in Table S3. We found evidence for three indirect associations between vocabulary and child outcomes, all via lower literacy at $8-9$ years. Lower vocabulary at 4-5 years predicted higher hyperactivity-inattention at 8-9 years (indirect effect $=$ $-.12,95 \%$ CI $[-.17,-.07])$; higher emotional symptoms at 8-9 years (indirect effect $=-.08,95 \%$ CI $[-.13,-.03])$; and higher conduct problems at $8-9$ years (indirect effect $=-.07,95 \%$ CI $[-.12,-.02])$.

For each set of latent growth factors, we found a negative association between the intercept and slope, indicating regression to the mean (i.e., the principle that children who start at the end of the distribution (i.e., very low or very high) are statistically more likely to move toward the center of the distribution than to move further out). Socioeconomic position was associated with intercepts for vocabulary and conduct problems, and the slope for hyperactivity-inattention, literacy, and peer problems at 8-9 years. Nonverbal intelligence was associated with the intercepts for vocabulary and emotional symptoms, and with literacy and peer problems at 8-9 years. The magnitude of the direct and indirect associations between intercepts and slopes for vocabulary and child outcomes (i.e., hyperactivity-inattention, conduct problems, and emotional symptoms) were larger or similar compared to the size of associations between the covariates (socioeconomic position and nonverbal intelligence) and child outcomes.

\section{Sensitivity Analyses}

Figure S1 presents data from sensitivity Model $1 \mathrm{~A}$, testing a variation of Model 1 by replacing teacher-report of literacy with the national assessment measure of reading. This model had good overall fit, $\chi^{2}[d f]=709.712$ [170], $p<.000 ;$ RMSEA $=.025,95 \%$ CI $[.023, .027] ;$ CFI $=.980 ;$ TLI $=.968$; SRMR $=.046$. Findings were similar to Model 1, with the exception that the association between child reading at 8 9 years and the intercept for emotional symptoms was not present. There were three indirect associations evident via lower reading achievement, including associations between lower vocabulary at 45 years and higher hyperactivity-inattention at 8 9 years (indirect effect $=-.13,95 \%$ CI $[-.20,-.07]$ ) and conduct problems at 8-9 years (indirect

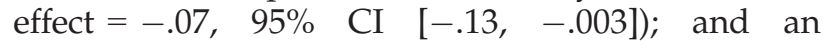


association between less rapid growth in vocabulary and higher hyperactivity-inattention at 8-9 years (indirect effect $=-.05,95 \% \mathrm{CI}[-.10,-.01])$.

Figure S2 presents data from sensitivity Model $1 \mathrm{~B}$, testing a second variation replacing motherreport of hyperactivity-inattention, conduct problems, and emotional symptoms with child selfreport measures. This model had good overall fit, $\chi^{2}[d f]=597.931[110], p<.000 ;$ RMSEA $=.030,95 \%$ CI $[.028, .032] ; \mathrm{CFI}=.969 ; \mathrm{TLI}=.943 ; \mathrm{SRMR}=.036$. This model varied more substantially from Model 1. There were two direct associations between vocabulary and child outcomes; lower vocabulary at 4-5 years was associated with higher emotional symptoms at 8-9 years and with a less rapid increase in emotional symptoms over time. We found six indirect associations. Lower vocabulary at 4-5 years was consistently associated with higher hyperactivity-inattention at 8-9 years (indirect effect $=-.05, \quad 95 \%$ CI $[-.08,-.03])$, emotional symptoms at 8-9 years (indirect effect $=-.09,95 \%$ CI $[-.13,-.05])$, and conduct problems at $8-9$ years (indirect effect $=-.06,95 \%$ CI $[-.10,-.03]$ ); and with less rapid growth in hyperactivity-inattention (indirect effect $=.03,95 \%$ CI $[.01, .06]$ ), emotional symptoms (indirect effect $=.08,95 \%$ CI $[.05, .12]$ ), and conduct problems (indirect effect $=.05,95 \% \mathrm{CI}$ $[.01, .09])$ between $8-9$ and $14-15$ years, all via lower literacy at $8-9$ years.

\section{Research Question 3}

Figure 2 and Table 2 present results from Model 2 , testing a subpopulation analysis for children below the 50th percentile for vocabulary at 4 5 years. The available sample was restricted by 576 children having missing data on vocabulary at 4 5 years (final sample, $N=2,120$ ). This model had good overall fit, $\chi^{2}[d f]=386.711$ [170], $p<.000$; RMSEA $=.025,95 \%$ CI $[.021, .028] ;$ CFI $=.979$; $\mathrm{TLI}=.967 ; \mathrm{SRMR}=.047$. Unstandardized and standardized results for total, total indirect, and direct effects are presented in Table S2, and the correlations between the independent and dependent variables in Table S3.

We found one direct association, where a higher slope (i.e., a more rapid increase) in vocabulary between 4-5 and 8-9 years was associated with a lower slope in hyperactivity-inattention between 8-9 and 14-15 years. We also found evidence for six indirect associations via low literacy at 8-9 years. Lower vocabulary at $4-5$ years predicted higher hyperactivity-inattention at 8-9 years (indirect effect $=-.11,95 \%$ CI $[-.17,-.06])$; higher emotional symptoms at 8-9 years (indirect effect $=$ $-.08,95 \%$ CI $[-.14,-.02])$; higher conduct problems at $8-9$ years (indirect effect $=-.08,95 \% \mathrm{CI}$ $[-.14,-.03]) ;$ and less rapid growth in conduct problems (indirect effect $=.07,95 \%$ CI [.01, .12]). Less rapid growth in vocabulary predicted higher hyperactivity-inattention at 8-9 years (indirect effect $=-.05,95 \% \mathrm{CI}[-.10,-.004])$, and higher conduct problems at 8-9 years (indirect effect $=$ $-.04,95 \%$ CI $[-.08,-.004])$.

\section{Discussion}

This study illustrates the value of exploring developmental trajectories in order to understand the association between children's receptive vocabulary and later hyperactivity-inattention, conduct problems, and emotional symptoms. Our results support prior research by showing associations between vocabulary at 4-5 years and hyperactivity-inattention, emotional symptoms, and conduct problems at 8-9 years. In addition, we found new evidence that the rate of growth in vocabulary between 4-5 and 8-9 years was associated with child hyperactivity-inattention at 8-9 years and the rate of growth in hyperactivity-inattention between 8-9 and 14-15 years. Child literacy emerged as a possible mechanism linking low vocabulary at 4-5 years with subsequent trajectories of hyperactivity-inattention, conduct problems, and emotional symptoms. These associations were generally consistent for children at or above compared to below the 50th percentile for vocabulary at age 4-5 years, highlighting the role of early receptive vocabulary, and the mediating role of literacy, in the development of behavioral and emotional difficulties, regardless of early language ability.

Our results suggest that the rate of growth in receptive vocabulary over childhood may influence later child outcomes over and above the known influence of vocabulary in early childhood. We found that a more rapid increase in vocabulary between 4-5 and 8-9 years was associated with higher child hyperactivity-inattention at 8-9 years (an unexpected finding, discussed next), and a less rapid increase in hyperactivity-inattention between 8-9 and 14-15 years. When these associations were tested again in the subpopulation analysis, we found evidence for indirect influences in the expected direction. For children below the 50th percentile for vocabulary at age $4-5$ years (i.e., 'lower' vocabulary group), a less rapid growth in 


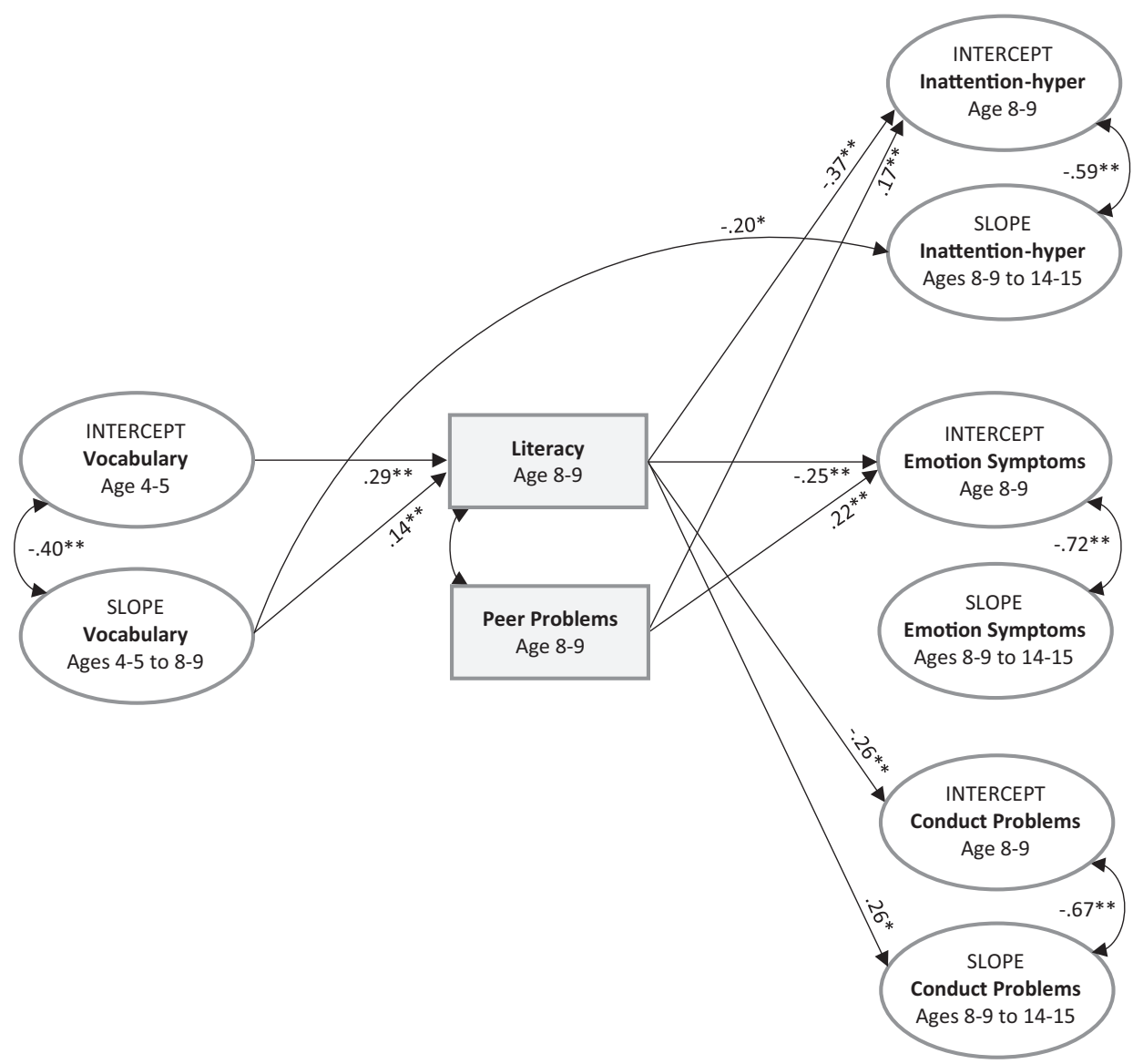

Figure 2. Findings for children below the 50th percentile for vocabulary at $4-5$ years $(N=2120)$, showing results $(<.05)$, from a latent growth curve model, with direct relations between trajectories of receptive vocabulary and mother-report of hyperactivity-inattention, conduct problems, and emotional symptoms; and indirect relations via peer problems and literacy.

Notes. Single-headed straight or curved lines represent standardized regression coefficients where $p<.05$. Models adjust for hyperactivity-inattention, conduct problems, and emotional symptoms at 4-5 years, socioeconomic position at 4-5 years, child age, and child nonverbal intelligence at 6-7 years. Emotion symptoms $=$ emotional symptoms.

$* p<.05 . * * p .01$.

vocabulary was associated with higher child hyperactivity-inattention and emotional symptoms at $8_{-}^{-}$ 9 years.

We found relatively consistent patterns of association for the full cohort compared to the subpopulation of children with lower vocabulary ability at 4-5 years. However, there were fewer direct associations evident in the subgroup, possibly due to reduced power to detect associations. There were also small differences whereby lower vocabulary scores and growth were associated with higher conduct problems at 8-9 years for children in the lower vocabulary group. Results from the sensitivity analyses also depicted a consistent pattern of indirect associations between vocabulary scores and growth and child outcomes, with two subtle differences. Although teacher-report of academic ability was related to both parent and child-report of emotional symptoms, the national assessment for reading achievement was not found to be associated with child emotional symptoms, showing that academic performance on this test did not appear to be altered for children with emotional symptoms. Further, findings based on parent-report of child outcomes highlighted direct associations between vocabulary and child hyperactivity; while childreport identified direct associations between vocabulary and child emotional symptoms, but not for hyperactivity-inattention.

\section{Counterintuitive Findings}

There were two sets of counterintuitive findings. The first unexpected finding related to children in the bottom 50th percentile for vocabulary at 45 years, and was echoed in the sensitivity analysis 
examining child-reported outcomes. We found indirect associations between lower vocabulary scores at 4-5 years and a less rapid increase in hyperactivity-inattention, emotional symptoms, and conduct problems over time via lower literacy at 8-9 years. These findings may be explained by regression to the mean principles. For example, our findings suggest that children with low vocabulary at $4-5$ years also had higher hyperactivity-inattention, emotional symptoms, and conduct problems at 8-9 years. Children who start at the end of the distribution (i.e., very low or very high) are statistically more likely to move toward the center of the distribution than to move further out.

Secondly, in the full cohort, we found direct associations between higher vocabulary scores at 45 years, or a more rapid increase in child vocabulary scores at 4-5 years, and higher scores for hyperactivity-inattention at 8-9 years. However, the indirect associations showed the opposite relations; that is, low vocabulary at $4-5$ years was associated with higher hyperactivity-inattention via literacy. These findings may indicate risk pathways for two distinct groups of children who go on to develop hyperactivity-inattention; those without vocabulary difficulties who present early with hyperactivityinattention (and hence have slower growth in these symptoms between 8-9 and 14-15 years), and those with poorer early vocabulary and slower vocabulary growth whose difficulties with hyperactivityinattention, emotional symptoms, and conduct problems become more apparent over time. These findings require further investigation.

\section{Implications for Theory}

Findings from the current study add to those from Petersen et al. (2013), and suggest potential for early language ability to influence subsequent hyperactivity-inattention, emotional and conduct problems, both directly or indirectly through academic experiences. Our findings support Beitchman and colleagues' model, suggesting that problems with literacy (or reading achievement) in middle childhood may arise due to low early vocabulary (Stanley, Petscher, \& Catts, 2018), leading to the development of behavioral and emotional problems (Beitchman et al., 1996). We add to theory by showing that these indirect associations also operate in relation to less rapid increases in vocabulary over early primary school years; thus emphasizing the importance of tracking children's vocabulary and language development over time. Further, consistent with findings from the Language and
Reading Research Consortium and Logan (2017), we found associations regardless of whether children were in the lower compared to the upper 50th percentile for vocabulary at $4-5$ years, indicating that small differences in early vocabulary and/or growth in vocabulary, even in children in the normal range for vocabulary development, are related to children's academic, behavioral and emotional functioning.

Our results do not support the 'Social Adaptation Model' (Redmond \& Rice, 1998), which hypothesized a central role of social problems in the association between language and child behavioral and emotional difficulties. We found that peer problems in children were independently associated with hyperactivity-inattention, conduct problems, and emotional symptoms, but in our study peer problems did not explain the association between vocabulary and subsequent behavioral and emotional difficulties. However, our study did not consider other types of language development (e.g., grammatical, discourse, or pragmatic skills), which may be more relevant to the Social Adaptation Model.

Our study focused on a particular sequence of associations, from early trajectories of vocabulary to later hyperactivity-inattention, conduct problems, and emotional symptoms, via academic ability and peer problems. In contrast, traditional models of attention deficit hyperactivity disorder (ADHD), emphasizing the neurobiological basis of the disorder, have tended to investigate academic functioning and peer problems as an outcome of ADHD (e.g., Arnold, Hodgkins, Kahle, Madhoo, \& Kewley, 2015; Spira \& Fischel, 2005). However, early social environmental factors such as socioeconomic status, parent mental health, and maternal smoking during pregnancy have long been considered important predictors of ADHD (Russell, Ford, Williams, \& Russell, 2016). More recently, research has explored Gene $\times$ Environment interactions and epigenetic processes that may mediate ADHD susceptibility (Mill \& Petronis, 2008). Although the precise nature of these processes remains poorly understood, evidence suggests that environmental and other factors influence epigenetic processes of child development, thus influencing susceptibility to disorders such as ADHD.

\section{Strengths}

A key strength of our study was that our findings address a number of methodological and theoretical gaps in prior research. Longitudinal cohort 
studies examining language and hyperactivity-inattention, conduct problems, and emotional symptoms have typically classified language difficulties in early childhood, often prior to school entry (Beitchman et al., 2001; Redmond \& Rice, 1998; St Clair et al., 2011; Tomblin et al., 2000). As hypothesized, our findings suggest that examining the rate of change in these constructs over childhood provides additional information about children's subsequent developmental pathways, over and above information gained from examining functioning at one time-point in early childhood. The rich data set of LSAC was a notable strength of the current study, allowing us to control for the known effects of a range of child, parent and family covariates, and to use a variety of measurement sources for the mediation and outcomes variables, enhancing confidence that the associations were not inflated by shared method variance.

The large sample size and repeated measures in LSAC also allowed the use of SEM and latent growth curve analysis. The SEM framework is currently the most robust approach by allowing mediation to be tested within a single step (instead of the previous four step process), providing model fit information (Gunzler, Chen, Wu, \& Zhang, 2013), and allowing comparison of direct and indirect effects, which assist in understanding whether proposed causal processes are supported empirically by the strength, direction, and timing of associations observed (Kenny, 2008). Although our effect sizes were small to moderate, they were of a similar magnitude to the effects of other well-established predictors of child behavioral and emotional difficulties, such as parenting, when modeled using the LSAC data (Westrupp, Mensah, Giallo, Cooklin, \& Nicholson, 2012); and were larger or of similar magnitude to the child and social demographic variables accounted for in the models. In this regard, our findings provide further evidence for the important associations between early child vocabulary development, academic ability, and later behavioral and emotional problems.

\section{Limitations}

Our study also had some limitations. Although the use of maximum likelihood estimation minimized the impact of participant attrition by allowing inclusion of all available information from participants, LSAC had higher attrition in more disadvantaged groups in which rates of vocabulary problems are known to be higher. Thus, our findings may not be fully representative of the
Australian population. The current study was limited by measures available in LSAC. Although widely used in longitudinal cohort studies, the SDQ is not a diagnostic assessment of child mental health problems. Replication of these models with more detailed child clinical assessment tools would provide a useful validation of the findings. Academic ability and peer problems were measured concurrently so it was not possible to test the direction of mediation effects between these two variables. Findings from a recent study of first graders in the United States also suggest the potential for reciprocal influences between receptive vocabulary, social skills, and literacy over a period of a year. This study was also limited by measurement of social skills at a single time-point, so future research should utilize repeated measures for a more reliable investigation of reciprocal influences over time (Sparapani et al., 2018).

The measure of receptive vocabulary was the sole repeated measure of language available in LSAC. Our focus on vocabulary has merit in light of the demonstrated importance of vocabulary development for phonological knowledge (Verhoeven, van Leeuwe, \& Vermeer, 2011) and broader reading comprehension and literacy (Ricketts, Nation, \& Bishop, 2007); and the demonstrated scope for intervention to improve child vocabulary skills, where the response is arguably more reliable than other aspects of language development (Law, Garrett, \& Nye, 2003). Nevertheless, an investigation of growth in other language skills may reveal different associations. Vocabulary and grammar skills have been shown to operate as unitary dimensions early in life but become more distinct over time (Language and Reading Research Consortium, 2015; Tomblin \& Zhang, 2006). More recent research by Lonigan and Milburn (2017) found that while vocabulary and syntax operated as distinct constructs from preschool to fifth grade, they were highly related, sharing $81 \%-88 \%$ of variance. Thus, in our study, the measure of vocabulary was likely to be a reliable estimate of global language ability. Promising research shows the importance of pragmatic language skills in relation to child and adolescent social development and mental health (Law et al., 2015), and it will be valuable to model these associations in future longitudinal research.

\section{Future Directions}

There may be potential to minimize increased risk through early interventions. If vocabulary or other aspects of language development are strongly 
associated with subsequent child behavior, there is a logical rationale for using vocabulary or language interventions to prevent the development of emotional and behavior problems. This is supported by evidence for both clinical and educational speech and language interventions at least in the shortterm (Law \& Garrett, 2004; Law et al., 2017). In addition, our findings show that the rate of growth in vocabulary over childhood may confer important information about subsequent risks for children. The follow-up period following interventions needs to be carefully considered. Provision of intervention based on assessment at a single time-point may result in missing out on additional support that would have been beneficial (Ukoumunne et al., 2012). Instead, our findings call for intervention methods focused on the developmental trajectory of vocabulary (Marulis \& Neuman, 2010), and early language-based literacy skills (Rogde, Hagen, Melby-Lervåg, \& Lervåg, 2016). These types of interventions highlight the role schools play in partnership with parents, to identify and monitor over time children who are falling behind. Given that lower growth in vocabulary may affect children who started school with average or above average ability, it is important that interventions monitor growth across the full spectrum of functioning.

There is a large body of work demonstrating the effectiveness of a number of classroom practices to promote children's vocabulary development, targeting active learning strategies, including semantic mapping, comparing and contrasting word meanings, creating definitions, using target words in new contexts, and promoting independent word learning (Lubliner \& Smetana, 2005; Marulis \& Neuman, 2010; McKeown \& Beck, 2014; Nash \& Snowling, 2006). These practices can be integrated into current curriculum rather than offered as additional specialist interventions for children with clinical levels of language difficulties, thus providing exposure and potential benefits to children across the spectrum of functioning. The importance of such practices for literacy development has long been recognized, but the relationship with later emotional and behavioral development has not. Thus, future directions for research and intervention should focus on the promotion of evidencebased classroom practices; long-term assessment and monitoring of vocabulary, language, and emotional and behavior problems over childhood incorporated into classroom practice, and following intervention; and advocacy to support the inclusion of oral language development in educational curricula beyond the early years.

\section{Conclusions}

Using data from this representative national cohort, we build on previous findings from clinical and population studies showing associations between language and hyperactivity-inattention, conduct problems, and emotional symptoms. In addition to the known effect of early receptive vocabulary problems, findings show that the developmental course of receptive vocabulary is associated with the trajectory of hyperactivity-inattention, conduct problems, and emotional symptoms over the transition from childhood to adolescence. Results highlight the importance of monitoring children through middle childhood and adolescence, and point to vocabulary-based classroom interventions as having a potential role in alleviating adolescent behavioral and emotional problems.

\section{References}

Arnold, L. E., Hodgkins, P., Kahle, J., Madhoo, M., \& Kewley, G. (2015). Long-term outcomes of ADHD academic achievement and performance. Journal of Attention Disorders. https://doi.org/10.1177/108705471456 6076

Australian Institute of Family Studies. (2015). Longitudinal Study of Australian Children data user guide. Melbourne, Vic: Australian Institute of Family Studies.

Bates, E., \& Goodman, J. C. (2001). On the inseparability of grammar and the lexicon: Evidence from acquisition. Language and Cognitive Processes, 12, 507-584. https:// doi.org/10.1080/016909697386628

Beitchman, J. H., Brownlie, E., \& Wilson, B. (1996). Linguistic impairment and psychiatric disorder: Pathways to outcome. In J. H. Beitchman, N. J. Cohen, M. M. Konstantareas, \& R. Tannock (Eds.), Language, learning, and behavior disorders: Developmental, biological, and clinical perspectives (pp. 493-514). New York, NY: Cambridge University Press.

Beitchman, J. H., Jiang, H., Koyama, E., Johnson, C. J., Escobar, M., Atkinson, L., . . . Vida, R. (2008). Models and determinants of vocabulary growth from kindergarten to adulthood. Journal of Child Psychology and Psychiatry, 49, 626-634. https://doi.org/10.1111/j.14697610.2008.01878.x

Beitchman, J. H., Wilson, B., Johnson, C. J., Atkinson, L., Young, A., Adlaf, E., . . . Douglas, L. (2001). Fourteenyear follow-up of speech/language-impaired and control children: Psychiatric outcome. Journal of the American Academy of Child E Adolescent Psychiatry, 40(1), 75-82. https: / / doi.org/10.1097/00004583-200101000-00019

Bennett, K. J., Lipman, E. L., Brown, S., Racine, Y., Boyle, M. H., \& Offord, D. R. (1999). Predicting conduct problems: Can high-risk children be identified in kindergarten and grade 1? Journal of Consulting and Clinical 
Psychology, 67, 470-480. https://doi.org/10.1037/0022006X.67.4.470

Blakemore, T., \& Strazdins, L. (2009). Measuring family socioeconomic position. Australian Social Policy, 8, 121168. Retrieved from http:/ / hdl.handle.net/10620/2908

Botting, N., \& Conti-Ramsden, G. (2000). Social and behavioural difficulties in children with language impairment. Child Language Teaching and Therapy, 16, 105-120. https: / / doi.org/10.1177/026565900001600201

Bretherton, L., Prior, M., Bavin, E., Cini, E., Eadie, P., \& Reilly, S. (2014). Developing relationships between language and behaviour in preschool children from the Early Language in Victoria Study: Implications for intervention. Emotional and Behavioural Difficulties, 19(1), 7-27. https: / / doi.org/10.1080/13632752.2013.854956

Byrne, B. (2012). Structural equation modeling with Mplus. New York, NY: Routledge.

Clegg, J., Law, J., Rush, R., Peters, T. J., \& Roulstone, S. (2015). The contribution of early language development to children's emotional and behavioural functioning at 6 years: An analysis of data from the Children in Focus sample from the ALSPAC birth cohort. Journal of Child Psychology and Psychiatry, 56(1), 67-75. https:/ /doi.org/ 10.1111/jcpp.12281

Daraganova, G., Edwards, B., \& Sipthorp, M. (2013). Using National Assessment Program Literacy and Numeracy (NAPLAN): LSAC Technical Paper No. 8. In H. Department of Families, Community Services and Indegenous Affairs (Ed.), Data in the Longitudinal Study of Australian Children (LSAC) (pp. 1-45). Melbourne, Vic: Australian Institute of Family Studies.

Dunn, L., \& Dunn, L. (1997). Peabody Picture Vocabulary Test (3rd ed.). Circle Pines, MN: AGS.

Eisenberg, N., Cumberland, A., Spinrad, T. L., Fabes, R. A., Shepard, S. A., Reiser, M., . . . Guthrie, I. K. (2001). The relations of regulation and emotionality to children's externalizing and internalizing problem behavior. Child Development, 72, 1112-1134. https://doi.org/ 10.1111/1467-8624.00337

Feeney, R., Desha, L., Ziviani, J., \& Nicholson, J. M. (2012). Health-related quality-of-life of children with speech and language difficulties: A review of the literature. International Journal of Speech-Language Pathology, 14(1), 59-72. https://doi.org/doi:10.3109/17549507.2011. 604791

Goh Kok Yew, S., \& O'Kearney, R. (2015). Early language impairments and developmental pathways of emotional problems across childhood. International Journal of Language $\mathcal{E}$ Communication Disorders, 50, 358-373. https://doi.org/10.1111/1460-6984.12142

Goodman, R. (1997). The Strengths and Difficulties Questionnaire: A research note. Journal of Child Psychology and Psychiatry, 38, 581-586. https://doi.org/10.1111/j. 1469-7610.1997.tb01545.x

Goodman, R. (2001). Psychometric Properties of the Strengths and Difficulties Questionnaire. Journal of the American Academy of Child $\mathcal{E}$ Adolescent Psychiatry, 40,
1337-1345. https://doi.org/10.1097/00004583-20011100000015

Goodman, R., Meltzer, H., \& Bailey, V. (1998). The Strengths and Difficulties Questionnaire: A pilot study on the validity of the self-report version. European Child and Adolescent Psychiatry, 7, 125-130. https://doi.org/ $10.1007 / \mathrm{s} 007870050057$

Gray, M., \& Sanson, A. (2005). Growing Up in Australia: The Longitudinal Study of Australian Children [online]. Family Matters, 75, 4-9. Availability: https://search.inf ormit.com.au/documentSummary; dn=052395322391224; res=IELFSC ISSN: 1030-2646. [cited 14 Jan 19].

Gunzler, D., Chen, T., Wu, P., \& Zhang, H. (2013). Introduction to mediation analysis with structural equation modeling. Shanghai Archives of Psychiatry, 25, 390.

Hu, L., \& Bentler, P. M. (1999). Cutoff criteria for fit indexes in covariance structure analysis: Conventional criteria versus new alternatives. Structural Equation Modeling: A Multidisciplinary Journal, 6(1), 1-55. https: / / doi.org/10.1080/10705519909540118

Im-Bolter, N., Cohen, N. J., \& Farnia, F. (2013). I thought we were good: Social cognition, figurative language, and adolescent psychopathology. Journal of Child Psychology and Psychiatry, 54, 724-732. https://doi.org/10. 1111/jcpp.12067

Kenny, D. A. (2008). Reflections on mediation. Organizational Research Methods, 11, 353-358. https://doi.org/10. 1177/1094428107308978

Kessler, R. C., Berglund, P., Demler, O., Jin, R., Merikangas, K. R., \& Walters, E. E. (2005). Lifetime prevalence and age-of-onset distributions of DSM-IV disorders in the national comorbidity survey replication. Archives of General Psychiatry, 62, 593-602. https://doi.org/10. 1001/archpsyc.62.6.593

Language and Reading Research Consortium. (2015). The dimensionality of language ability in young children. Child Development, 86, 1948-1965.

Language and Reading Research Consortium., \& Logan, J. (2017). Pressure points in reading comprehension: A quantile multiple regression analysis. Journal of Educational Psychology, 109, 451.

Law, J., Charlton, J., Dockrell, J., Gascoigne, M., McKean, C., \& Theakston, A. (2017). Early language development: Needs, provision, and intervention for preschool children from socioeconomically disadvantage backgrounds. Retrieved from https:/ / educationendowmentfoundation.org.uk/public/ files/Law_et_al_Early_Language_Development_final.pdf Law, J., \& Garrett, Z. (2004). Speech and language therapy: Its potential role in CAMHS. Child and Adolescent Mental Health, 9(2), 50-55. https://doi.org/10.1111/j. 1475-3588.2004.00081.x

Law, J., Garrett, Z., \& Nye, C. (2003). Speech and language therapy interventions for children with primary speech and language delay or disorder. Cochrane Database of Systematic Reviews, 3, CD004110. https://doi. org/10.1002/14651858.cd004110 
Law, J., Plunkett, C. C., \& Stringer, H. (2012). Communication interventions and their impact on behaviour in the young child: A systematic review. Child Language Teaching and Therapy, 28(1), 7-23. https://doi.org/10. $1177 / 0265659011414214$

Law, J., Rush, R., Clegg, J., Peters, T., \& Roulstone, S. (2015). The role of pragmatics in mediating the relationship between social disadvantage and adolescent behavior. Journal of Developmental E Behavioral Pediatrics, 36, 389-398. https://doi.org/10.1097/DBP.00000000 00000180

Lawrence, D., Johnson, S., Hafekost, J., Boterhoven de Haan, K., Sawyer, M., Ainley, J., \& Zubrick, S. R. (2015). The mental health of children and adolescents: Report on the second Australian child and adolescent survey of mental health and wellbeing. Canberra, ACT: Department of Health.

Longobardi, E., Spataro, P., Putnick, D. L., \& Bornstein, M. H. (2017). Do early noun and verb production predict later verb and noun production? Theoretical implications. Journal of Child Language, 44, 480-495. https:/ / doi.org/10.1017/S0305000916000064

Lonigan, C. J., \& Milburn, T. F. (2017). Identifying the dimensionality of oral language skills of children with typical development in preschool through fifth grade. Journal of Speech, Language, and Hearing Research, 60, 21852198. https: / / doi.org/10.1044/2017_JSLHR-L-15-0402

Lubliner, S., \& Smetana, L. (2005). The effects of comprehensive vocabulary instruction on Title I students' metacognitive word-learning skills and reading comprehension. Journal of Literacy Research, 37, 163-200. https:/ / doi.org/10.1207/s15548430j1r3702_3

MacKinnon, D. P., Fairchild, A. J., \& Fritz, M. S. (2007). Mediation analysis. Annual Review of Psychology, 58, 593. https://doi.org/10.1146/annurev.psych.58.110405. 085542

MacKinnon, D. P., Lockwood, C. M., \& Williams, J. (2004). Confidence limits for the indirect effect: Distribution of the product and resampling methods. Multivariate Behavioral Research, 39, 99-128. https://doi.org/ 10.1207/s15327906mbr3901_4

Marulis, L. M., \& Neuman, S. B. (2010). The effects of vocabulary intervention on young children's word learning: A meta-analysis. Review of Educational Research, 80, 300-335. https://doi.org/10.3102/00346543 10377087

McKeown, M. G., \& Beck, I. L. (2014). Effects of vocabulary instruction on measures of language processing: Comparing two approaches. Early Childhood Research Quarterly, 29, 520-530. https://doi.org/10.1016/j.ecre sq.2014.06.002

Menting, B., van Lier, P. A. C., \& Koot, H. M. (2011). Language skills, peer rejection, and the development of externalizing behavior from kindergarten to fourth grade. Journal of Child Psychology and Psychiatry, 52(1), 72-79. https://doi.org/10.1111/j.1469-7610.2010.02279.x

Mill, J., \& Petronis, A. (2008). Pre- and peri-natal environmental risks for attention-deficit hyperactivity disorder
(ADHD): The potential role of epigenetic processes in mediating susceptibility. Journal of Child Psychology and Psychiatry, 49, 1020-1030. https://doi.org/10.1111/j. 1469-7610.2008.01909.x

Mok, P. L. H., Pickles, A., Durkin, K., \& Conti-Ramsden, G. (2014). Longitudinal trajectories of peer relations in children with specific language impairment. Journal of Child Psychology and Psychiatry, 55, 516-527. https:// doi.org/10.1111/jcpp.12190

Morgan, P. L., Farkas, G., Hillemeier, M. M., Hammer, C. S., \& Maczuga, S. (2015). 24-Month-Old Children With Larger Oral Vocabularies Display Greater Academic and Behavioral Functioning at Kindergarten Entry. Child Development, 86(5), 1351-1370. https://doi.org/10. $1111 /$ cdev.12398.

Muthén, L. K., \& Muthén, B. O. (1998-2010). Mplus user's guide. Los Angeles, CA: Author.

Nash, H., \& Snowling, M. (2006). Teaching new words to children with poor existing vocabulary knowledge: A controlled evaluation of the definition and context methods. International Journal of Language $\mathcal{E}$ Communication Disorders, 41, 335-354. https://doi.org/10.1080/ 13682820600602295

Petersen, I. T., Bates, J. E., D'Onofrio, B. M., Coyne, C. A., Lansford, J. E., Dodge, K. A., ... Van Hulle, C. A. (2013). Language ability predicts the development of behavior problems in children. Journal of Abnormal Psychology, 122, 542-557. https://doi.org/10.1037/ a0031963

Redmond, S. M., \& Rice, M. L. (1998). The socioemotional behaviors of children with SLI: Social adaptation or social deviance? Journal of Speech, Language, and Hearing Research, 41, 688-700. https://doi.org/10.1044/jslhr. 4103.688

Reilly, S., Wake, M., Ukoumunne, O. C., Bavin, E., Prior, M., Cini, E., . . Bretherton, L. (2010). Predicting language outcomes at 4 years of age: Findings from Early Language in Victoria Study. Pediatrics, 126, e1530e1537. https://doi.org/10.1542/peds.2010-0254

Ricketts, J., Nation, K., \& Bishop, D. V. M. (2007). Vocabulary is important for some, but not all reading skills. Scientific Studies of Reading, 11, 235-257. https://doi. org/10.1080/10888430701344306

Rogde, K., Hagen, A. M., Melby-Lervåg, M., \& Lervåg, A. (2016). The effect of linguistic comprehension training on language and reading comprehension: A systematic review. Campbell systematic reviews. Oslo, Norway: The Campbell Library.

Rothman, S. (2003a). An Australian version of the Adapted PPVT-III for use in research. Melbourne, Vic: Australian Council for Educational Research.

Rothman, S. (2003b). Data issues paper no. 2 report on adapted PPVT-III and who am i? Melbourne, Vic: Australian Council for Educational Research.

Rothman, S. (2009). The LSAC academic rating scale score. Unpublished paper. Melbourne, Vic: ACER.

Russell, A. E., Ford, T., Williams, R., \& Russell, G. (2016). The association between socioeconomic disadvantage 
and attention deficit/hyperactivity disorder (ADHD): A systematic review. Child Psychiatry \& Human Development, 47, 440-458. https://doi.org/10.1007/s10578-0150578-3

Schoon, I., Parsons, S., Rush, R., \& Law, J. (2010). Children's language ability and psychosocial development: A 29-year follow-up study. Pediatrics, 126(1), e73-e80. https:/ / doi.org/10.1542/peds.2009-3282

Sipthorp, M., \& Daraganova, G. (2011). LSAC technical paper no. 9: Wave 4 weights. Melbourne, Vic: Australian Institute of Family Studies.

Snowling, M. J., Duff, F. J., Nash, H. M., \& Hulme, C. (2016). Language profiles and literacy outcomes of children with resolving, emerging, or persisting language impairments. Journal of Child Psychology and Psychiatry, 57, 1360-1369. https://doi.org/10.1111/jcpp.12497

Soloff, C., Lawrence, D., \& Johnstone, R. (2005). Sample design (LSAC technical paper No. 1). Melbourne, Vic: Australian Institute of Family Studies.

Soloff, C., Sanson, A., Wake, M., \& Harrison, L. (2007). Enhancing longitudinal studies by linkage to national databases: Growing up in Australia, the Longitudinal Study of Australian Children. International Journal of Social Research Methodology, 10, 349-363. https://doi. org/10.1080/13645570701677060

Song, S., Su, M., Kang, C., Liu, H., Zhang, Y., McBrideChang, C., . . . Shu, H. (2015). Tracing children's vocabulary development from preschool through the schoolage years: An 8-year longitudinal study. Developmental Science, 18, 119-131. https://doi.org/10.1111/desc.12190

Sparapani, N., Connor, C. M., McLean, L., Wood, T., Toste, J., \& Day, S. (2018). Direct and reciprocal effects among social skills, vocabulary, and reading comprehension in first grade. Contemporary Educational Psychology, 53, 159167. https:/ / doi.org/10.1016/j.cedpsych.2018.03.003

Spira, E. G., \& Fischel, J. E. (2005). The impact of preschool inattention, hyperactivity, and impulsivity on social and academic development: A review. Journal of Child Psychology and Psychiatry, 46, 755-773. https:// doi.org/10.1111/j.1469-7610.2005.01466.x

St Clair, M. C., Pickles, A., Durkin, K., \& Conti-Ramsden, G. (2011). A longitudinal study of behavioral, emotional and social difficulties in individuals with a history of specific language impairment (SLI). Journal of Communication Disorders, 44, 186-199. https://doi.org/ 10.1016/j.jcomdis.2010.09.004

Stanley, C. T., Petscher, Y., \& Catts, H. (2018). A longitudinal investigation of direct and indirect links between reading skills in kindergarten and reading comprehension in tenth grade. Reading and Writing, 31, 133-153. https: / / doi.org/10.1007/s11145-017-9777-6

Tomblin, J. B., \& Zhang, X. (2006). The dimensionality of language ability in school-age children. Journal of Speech, Language, and Hearing Research, 49, 1193-1208. https:/ / doi.org/10.1044/1092-4388(2006/086)
Tomblin, J. B., Zhang, X., Buckwalter, P., \& Catts, H. (2000). The association of reading disability, behavioral disorders, and language impairment among second-grade children. The Journal of Child Psychology and Psychiatry, 41, 473-482. https:/ / doi.org/10.1111/1469-7610.00632

Ukoumunne, O., Wake, M., Carlin, J., Bavin, E., Lum, J., Skeat, J., . . . Reilly, S. (2012). Profiles of language development in pre-school children: A longitudinal latent class analysis of data from the Early Language in Victoria Study. Child: Care, Health and Development, 38, 341-349.

Verhoeven, L., van Leeuwe, J., \& Vermeer, A. (2011). Vocabulary growth and reading development across the elementary school years. Scientific Studies of Reading, 15 (1), 8-25. https://doi.org/10.1080/10888438.2011.536125

Visser, J. H., Ende, J. A. N., Koot, H. M., \& Verhulst, F. C. (1999). Continuity of psychopathology in youths referred to mental health services. Journal of the American Academy of Child E Adolescent Psychiatry, 38, 1560-1568. https://d oi.org/10.1097/00004583-199912000-00018

Wechsler, D. (2003). Wechsler Intelligence Scale for Children-fourth edition (WISC-IV). San Antonio, TX: The Psychological Corporation.

Westrupp, E. M., Mensah, F. K., Giallo, R., Cooklin, A., \& Nicholson, J. M. (2012). Mental health in 'low-to-moderate risk' preterm, low birth weight and small for gestational age children at 4-5 years: The role of early maternal parenting. Journal of the American Academy of Child and Adolescent Psychiatry, 51, 313-323. https:// doi.org/10.1016/j.jaac.2011.12.004

\section{Supporting Information}

Additional supporting information may be found in the online version of this article at the publisher's website:

Figure S1. Sensitivity Analysis Testing Indirect Relations Via Child Academic Achievement in Reading in Year 3 (Based on National Assessment Program-Literacy and Numeracy Scores)

Figure S2. Sensitivity Analysis Testing ChildReport of Hyperactivity-Inattention, Conduct Problems, and Emotional Symptoms

Figure S3. Histograms Showing Distributions for Final Model Variables

Table S1. Confidence Intervals of Unstandardized and Standardized Total, Total Indirect, and Direct Effects for Model $1(N=4,983)$

Table S2. Confidence Intervals of Unstandardized and Standardized Total, Total Indirect, and Direct Effects for Model 2 (Subpopulation, $N=2,120$ )

Table S3. Bivariate Correlations Between Independent and Dependent Variables in Models 1 and 2 